\title{
Analysis of highly accurate rain intensity measurements from a field test site
}

\author{
L. G. Lanza ${ }^{1}$, E. Vuerich ${ }^{2}$, and I. Gnecco ${ }^{1}$ \\ ${ }^{1}$ Department of Construction, Environmental and Territorial Engineering, University of Genova, 1 Montallegro, 16145 \\ Genova, Italy \\ ${ }^{2}$ Italian Meteorological Service - Centre of Meteorological Experimentations (ReSMA), km 20, 100 Braccianese Claudia, \\ 00062 Bracciano, Italy
}

Received: 15 October 2009 - Revised: 16 February 2010 - Accepted: 17 February 2010 - Published: 9 March 2010

\begin{abstract}
In the course of the recent WMO international instrument intercomparison in the field and the associated specific laboratory tests, highly accurate rainfall intensity measurements have been collected and made available for scientific investigation. The resulting high quality data set (contemporary one-minute rainfall intensity data from 26 gauges based on various measuring principles) constitutes an important resource to provide insights into the expected behaviour of rain intensity gauges in operational conditions and further useful information for National Meteorological Services and other users. A few aspects of the analysis of one-minute resolution rain intensity measurements are discussed in this paper, focusing on the observed deviations from a calculated reference intensity based on four pit gauges. Results from both catching and non-catching type gauges are discussed in relation with suitable tolerance limits obtained as a combination of the estimated uncertainty of the reference intensity and the WMO accuracy limits for rainfall intensity measurements. It is shown that suitably post-processed weighing gauges and tipping-bucket rain gauges had acceptable performance, while none of the non-catching rain gauges agreed well with the reference.
\end{abstract}

\section{Introduction}

The accuracy of rainfall intensity measurements obtained from tipping-bucket and other types of rain gauges, and their compared performance, is a topical issue in hydrology and meteorology (see e.g. Tokay et al., 2003; Molini et al., 2005a;

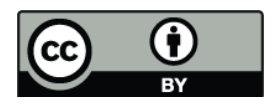

Correspondence to: L. G. Lanza (luca.lanza@unige.it)
Pavlyukov, 2007; Ren and Li, 2007; Keefer et al., 2008). Following Michaelides (2009), "measurements at the ground have been proved indispensable, despite advances in several areas of remotely sensing of precipitation. Ground truth seems to be inseparable from any study on precipitation. A better understanding of the behaviour of precipitation on the ground with direct measurements can lead to more effective estimations by using other methodologies".

In particular, in view of the very high variability of the rainfall intensity, measurements at a one-minute time scale are crucial to enable proper measures be taken to mitigate the impact of intense events, especially within the urban environment, and save lives, property and infrastructures. As the return period of heavy rainfall events is large, long-term records of highly accurate rainfall intensity data are sought to reliably estimate the probability of occurrence of heavy rainfall at a given location and time (see e.g. La Barbera et al., 2002 and Molini et al., 2005b for an assessment of the propagation of rain gauge measurement errors on the most common statistics of rainfall extremes). Such measurements would also be used for better design of structures (building, construction works) and infrastructure (drainage) to mitigate severe weather impact.

Heavy rainfall is also the origin of flash floods and other types of floods or weather related disasters. The impact of various types of natural and anthropogenic disasters is annually reported by CRED (Centre for Research on the Epidemiology of Disasters). In their statistical review for 2008 it is noted that, as in previous years, hydrological and meteorological disasters were the main contributors to the overall picture (Rodriguez et al., 2009). Though fewer disasters occurred in 2008 compared to 2000-2007 (see Fig. 1), events had a larger impact on human settlements.

Published by Copernicus Publications on behalf of the European Geosciences Union. 


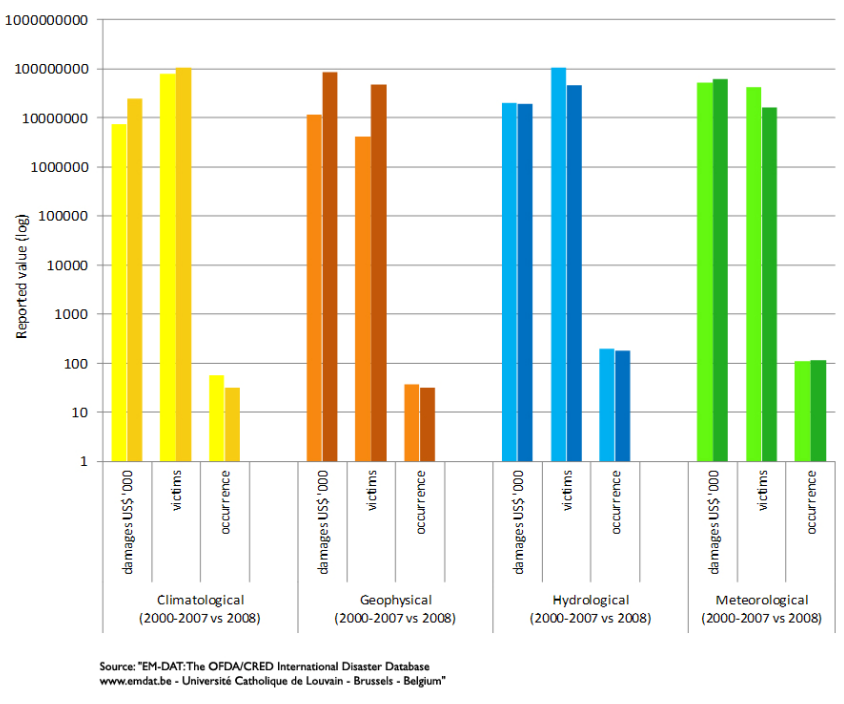

Fig. 1. The impacts of natural disasters by disaster sub-group (after Rodriguez et al., 2009): 2008 (right bars) versus 2000-2007 annual average (left bars).

Rainfall intensity at the ground is measured with various technologies, and the development of new solutions based on innovative measurement principles has the potential to lead to high accuracy and reliability. Further to the traditional and still widely employed tipping-bucket rain gauges, weighing gauges and various types of non-catching gauges have been developed and are now proposed/employed for operational use.

The World Meteorological Organisation (WMO) promoted a first Expert Meeting on rainfall intensity measurements already in 2001 in Bratislava (Slovakia). Further to the definition of rainfall intensity and the related reference accuracy and resolution, the convened experts suggested to organise an international intercomparison of rainfall intensity measurement instruments, to be held first in the laboratory and then in the field.

The Laboratory Intercomparison (2004-2005) was held at the recognised laboratories of Météo France, KNMI (The Netherlands), and the University of Genoa (Italy) and addressed the accuracy of catching type rain gauges under controlled, constant flow rate conditions (Lanza et al., 2005). The objectives of the follow-up intercomparison in the field were to assess and compare counting and catching errors of both catching and non-catching type of rainfall intensity gauges (Vuerich et al., 2009a; Lanza and Vuerich, 2009), with special consideration given to high rainfall intensities. Further objectives were to offer advice on improvements of instruments and precipitation measurements. The majority of the instruments involved were catching type gauges comprising tipping-bucket gauges, weighing gauges and one water level gauge. Non-catching rain gauges were represented by optical and impact disdrometers, one optical/capacitive gauge and one microwave radar gauge.
The resulting high quality data set (one-minute rainfall intensity data) constitutes an important scientific resource, suitable to provide further insights into the behaviour of both catching and non-catching types of gauges and their compared performance. After a synthetic description of the available dataset is provided in Sect. 2, a few aspects of the analysis of high resolution rain intensity measurements are discussed in Sect. 3, focusing on the observed performance of various instruments based on different measuring principles. Some conclusions are finally drawn about the feasibility to measure and compare rainfall intensities on a one-minute time scale and on the achievable measurement uncertainties.

\section{The WMO Intercomparison dataset}

Following the request of users and the recommendation of CIMO-XIV, the WMO Expert Team on Surface-Based Instrument Intercomparison and Calibration Methods (ET on SBII\&CM) and the International Organizing Committee (IOC) on Surface-Based Instrument Intercomparisons jointly performed the WMO Field Intercomparison of Rainfall Intensity (RI) Gauges from October 2007 to April 2009. The campaign was held at the Centre of Meteorological Experimentations (ReSMA) of the Italian Meteorological Service located in Vigna di Valle - Italy.

The intercomparison hosted 26 different rainfall intensity gauges and was unique as to the number of instruments and variability of techniques used. In the field, all gauges were compared with a Rainfall Intensity (RI) composite working reference at a one-minute resolution in time, consisting of a set of reference catching type rain gauges positioned in a standard pit.

The intercomparison site was built at the experimental area of ReSMA (see Fig. 2). It is a flat $400 \mathrm{~m}^{2}$ grass field, equipped with 34 concrete platforms (4 corner-platforms and 30 evenly distributed platforms) and a central 4-fold ISO standard pit for the installation of the set of reference RI gauges. Each platform is provided with power supply (AC and VDC), serial communication converters, 8 free and 8 coupled high quality double shielded acquisition cables and low voltage threshold discharge protections.

Prior to installation in the field all reference gauges and the catching type instruments were calibrated in the WMO recognized laboratory at the University of Genoa (Lanza and Stagi, 2009). Calibration procedures were based on recommendations of the previous WMO Laboratory Intercomparison of RI Gauges (Lanza et al., 2005; Lanza and Stagi, 2008) which were further developed to allow an assessment of the one-minute measurement uncertainty under controlled, constant flow rate conditions. A periodic testing of catching type rain gauges using a portable field calibration device was also performed on site (Vuerich et al., 2009b).

The Field Intercomparison has been continuously managed for 18 months in all weather conditions, excluding three 


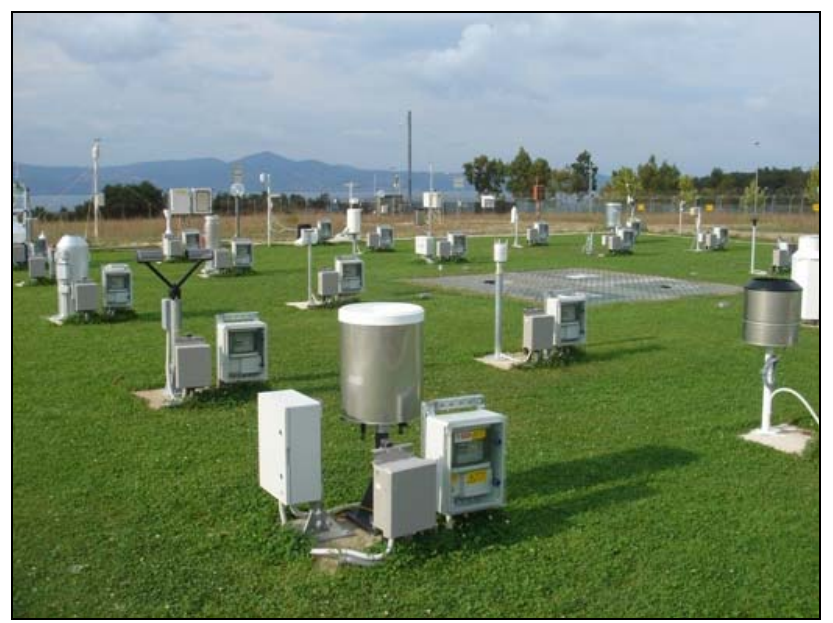

Fig. 2. The WMO Field Intercomparison test bed in Vigna di Valle (Italy).

scheduled and one extraordinary maintenance service of data acquisition system and field cabling (totally 23 days), and the periodic maintenance works of rain gauges. The total availability of one-minute data was $95.4 \%$, approximately $7.4 \times 10^{5}$ minute-data of all weather conditions (rain and no rain conditions). The number of precipitation events (collected in daily files) was 162 (156 rain events and 6 hail or mixed rain/hail events). The following criteria were applied for selecting suitable precipitation events in order to be included in the final dataset of the intercomparison:

- Events were chosen among those observed during the period from 13 May, 2008 to 30 April, 2009. Problems of synchronization and other critical malfunctions were all solved before 13 May, 2008. The only exception is the event of 30 October, 2007, showing the highest rainfall rate that occurred during the previous period;

- Events used to retrieve the weights for calculation of the reference RI (see below) are characterized by at least two consecutive minutes with one-minute RI greater than $6 \mathrm{~mm} \times \mathrm{h}^{-1}$;

- Events used for the RI data analysis are characterized by at least two consecutive minutes with one-minute RI greater than $12 \mathrm{~mm} \times \mathrm{h}^{-1}$.

According to the first criterion, the number of daily events considered for the Field Intercomparison was 85. This was the basis for the "reduced" Field Intercomparison (FI) dataset. According to the second criterion, 79 events (out of 85 ) were used for the calculation of reference RI. According to the third criterion, 43 events (out of 79) were used for the data analysis of all rain gauges. According to the daily reports from the Quality Control (QC), the total availability of valid data was $98.2 \%$. Table 1 reports a summary of the available data included in the dataset.
In order to report the specific performance of each rain gauge in field conditions, a number of graphs and comments were produced and reported in a series of Data Sheets prepared for each instrument, and annexed to the Final Report of the intercomparison (Vuerich et al., 2009a). They contain, among others, the following information:

- Constant flow response assessment (from the laboratory tests);

- Step response evaluation (from the laboratory tests);

- Calibration stability throughout the intercomparison period (field calibrations results);

- Individual rain gauge measurements against the reference RI, showing the spreading of one-minute rain intensity measurements, a tolerance region and the line of perfect agreement;

- Relative Deviations (RD) of rain gauge measurements against the reference RI on a one-minute time scale, showing the spreading of experimental data and the tolerance region;

- RDs of rain gauge measurements against the reference $\mathrm{RI}$ variations in time (rates of increase/decrease) on a one-minute time scale, showing the spreading of experimental data;

- Quality Assurance information including the relevant quality management aspects for each rain gauge, such as the availability of valid data per each single instrument, maintenance aspects and any malfunction possibly occurred during the intercomparison period.

The Relative Deviations of both catching and non-catching type of gauges against the working reference are considered for the investigations reported in this paper.

An Automated Quality Control was part of the Quality Assurance (QA) plan to ensure proper data and metadata acquisition, storage, processing and analysis. All information on visual inspection, observations, maintenance and repair was stored in an electronic logbook. The local staff performed a daily visual check, cleaning of instruments when necessary, and calibration status checks when required by instruments technical manuals. The local weather forecast was used for planning of preventive maintenance. A suitable portable device for field calibration of catching type instruments was provided by the University of Genova to ReSMA and was used for performing field tests. During the intercomparison period QA reports were produced by the site manager with all relevant information about QA operations and field tests results. 
Table 1. Summary of the available data included in the Field Intercomparison dataset.

\begin{tabular}{ll}
\hline Total Availability (TA) of one-minute data (rain/no rain) & $95.4 \%$ \\
\hline One-minute valid data (rain/no rain): percentage of TA denoting valid data according to the QC & $98.2 \%$ \\
Total number of precipitation daily events & 162 (Full Dataset) \\
Hail and Mixed Rain/Hail events & 6 events \\
Number of correctly synchronized events & 85 (Reduced Dataset) \\
Number of events used for calculation of reference RI & 79 \\
Number of events selected for the intercomparison & 43 \\
Rainfall accumulated over the intercomparison period & $1325 \mathrm{~mm}$
\end{tabular}

\section{Data analysis and results}

The working RI reference was obtained as the best estimation of the one-minute RI "true" value from the reference gauges located in a pit, initially selected as two corrected Tipping Bucket Rain Gauges (TBRG with correction algorithm) and two Weighing Gauges (WG) with the shortest step response and the highest accuracy. The determination of a reference value of the rainfall intensity was fundamental for defining the baseline for the intercomparison. Statistical evaluation of the one-minute RI reference was applied, making use of a weighted average obtained from the rainfall intensities measured by the four reference instruments.

The weights were calculated taking into account both a global statistical parameter, obtained from the whole data set, and also the evaluation of each single event from which the average is calculated. The evaluation of each single event is introduced in the weights by means of a "gross" parameter determined on the basis of a detailed examination of the RI data for that event. The evaluation of the uncertainty of this reference value is very complex because the physical contributions due to the dynamics of the instruments, their response functions and environmental related effects are not known. A normal distribution of the deviations of the rainfall intensity measurements of the pit gauges is assumed (see Fig. 3 for a graphical verification of this hypothesis) and the standard deviation of the distribution with respect to the reference intensity is calculated. It is common practice in metrology (JCGM, 2008) to express the uncertainty as "expanded uncertainty" in relation to the "statistical coverage interval", therefore the $95 \%$ confidence level is used for all measurements. Since the measurement uncertainty is assumed to be independent on the rainfall intensity, the RI reference expanded uncertainty $(95 \%)$ is calculated as $\mathrm{U}\left(\mathrm{RI}_{\mathrm{ref}}\right)=2 \sigma$. The relative uncertainty is thus obtained as $\mathrm{u}_{\mathrm{rel}}\left(\mathrm{RI}_{\mathrm{ref}}\right)=\left(\mathrm{U}\left(\mathrm{RI}_{\mathrm{ref}}\right) / \mathrm{RI}_{\mathrm{ref}}\right) \times 100$.

In order to compare the gauges with each other and to assess their agreement with the user uncertainty requirements, deviations from the reference intensity were analysed and a tolerance region was established. For the calculation of the tolerance region we assumed the WMO required measure-

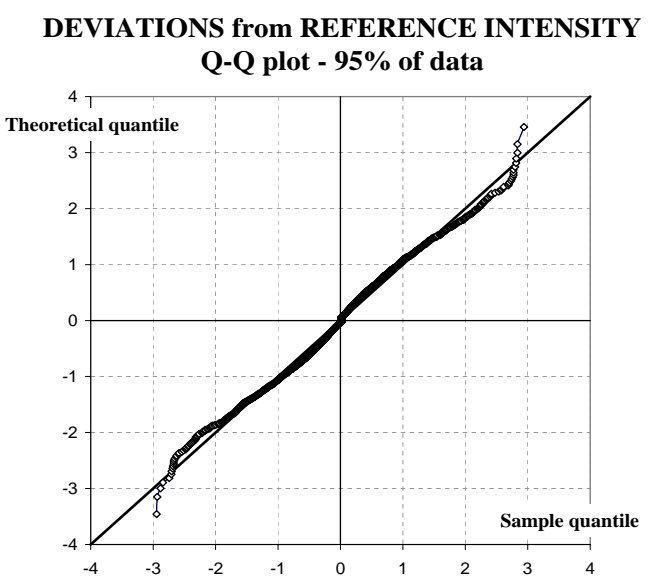

Fig. 3. Graphical normality test for the deviations of the pit gauges from the reference intensity. A reduced sample size (central $95 \%$ of the whole set of data) is used to avoid the influence of extremes.

ment uncertainty of $5 \%$ for each rainfall intensity gauge according to the WMO Guide to Meteorological Instruments and Methods of Observation (WMO, 2008). The tolerance region is composed of this $5 \%$ uncertainty and of the uncertainty of the reference, thus its value is finally calculated as: $\left(\mathrm{u}_{\mathrm{rel}}\left(\mathrm{RI}_{\mathrm{ref}}\right)^{2}+5^{2}\right)^{1 / 2}(\%)$.

For the one-minute data, the calculated uncertainty of the reference is $\mathrm{U}\left(\mathrm{RI}_{\mathrm{ref}}\right)=4.3 \mathrm{~mm} \times \mathrm{h}^{-1}$. The relative uncertainty of the reference was therefore found to be below $5 \%$ only for intensities above $90 \mathrm{~mm} \times \mathrm{h}^{-1}$. Below $90 \mathrm{~mm} \times \mathrm{h}^{-1}$ the relative uncertainty of the reference values was higher than the $5 \%$ required measurement uncertainty provided in the CIMO Guide (WMO, 2008).

The plots reported in Fig. 4 in this section illustrate the trend of the deviations of each instrument across the whole dataset against the RI composite working reference, where the trend line is obtained from a power law fitting of experimental data in the form:

$\mathrm{RI}=a \cdot \mathrm{RI}_{\text {ref }}^{b}$

where $a$ and $b$ are constant parameters (see Table 2 for a list of a, b and $R^{2}$ values). In order to assess the accuracy of 

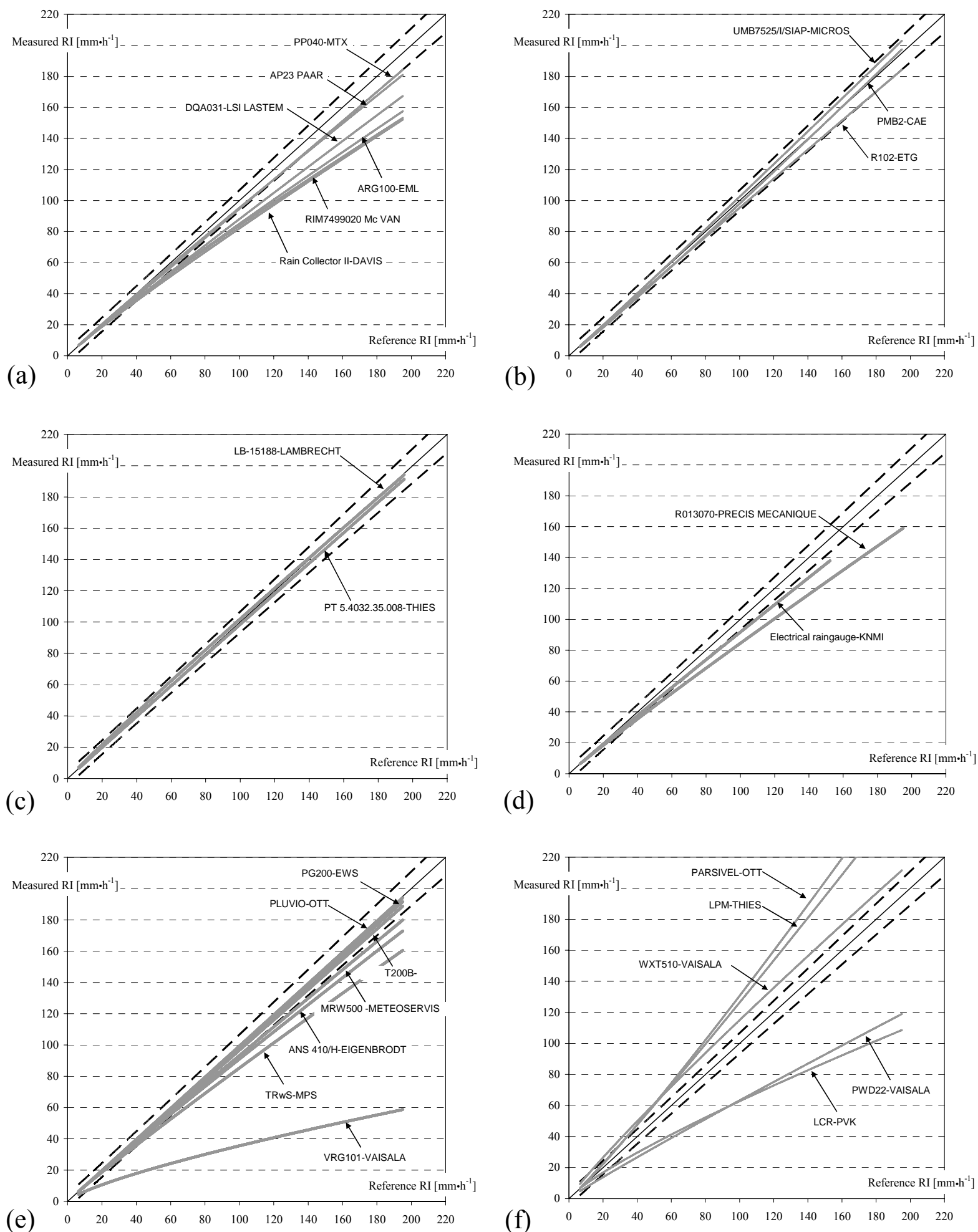

Fig. 4. Comparison between the measured and reference rainfall intensity for various classes of rain gauges: non corrected TBRs (a), software corrected TBRs (b), pulse corrected TBRs (c), mechanically corrected TBRs or level gauges (d), weighing gauges (e) and gauges based on other measuring principles (f). 
Table 2. Parameters of the regression curves $\mathrm{RI}=\mathrm{a} \times\left(\mathrm{RI}_{\mathrm{ref}}\right)^{b}$ reported in Fig. 4 (from a to f) for the instruments involved in the intercomparison.

\begin{tabular}{llllllll}
\hline rain gauge & $\mathrm{a}$ & $\mathrm{b}$ & $R^{2}$ & rain gauge & $\mathrm{a}$ & $\mathrm{b}$ & $R^{2}$ \\
\hline RIM7499020/McVan & 1.31 & 0.90 & 0.68 & VRG101/VAISALA & 1.12 & 0.75 & 0.12 \\
AP23/PAAR & 1.15 & 0.96 & 0.85 & PLUVIO/OTT & 0.98 & 1.00 & 0.90 \\
R013070/PRECIS-MECANIQUE & 1.08 & 0.95 & 0.77 & PG200/EWS & 0.98 & 1.00 & 0.81 \\
PT 5.4032.35.008/THIES & 1.01 & 0.99 & 0.85 & T200B/GEONOR & 0.96 & 1.00 & 0.89 \\
R 102/ETG & 1.01 & 0.99 & 0.88 & TRwS/MPS & 1.09 & 0.95 & 0.59 \\
DQA031/LSI LASTEM & 1.06 & 0.96 & 0.72 & PWD22/VAISALA & 0.81 & 0.94 & 0.51 \\
UMB7525/I/SIAP-MICROS & 0.92 & 1.02 & 0.73 & PARSIVEL/OTT & 0.82 & 1.10 & 0.77 \\
PM B2/CAE & 0.78 & 1.05 & 0.87 & LPM/THIES & 0.93 & 1.07 & 0.80 \\
RAIN COLLECTOR II/DAVIS & 1.16 & 0.92 & 0.73 & WXT510/VAISALA & 1.72 & 0.91 & 0.74 \\
LB/15188/LAMBRECHT & 1.21 & 0.96 & 0.81 & ANS 410/H/EIGENBRODT & 1.09 & 0.96 & 0.67 \\
PP040/MTX & 0.96 & 1.0 & 0.79 & Electrical raingauge/KNMI & 1.05 & 0.97 & 0.82 \\
ARG100/EML & 1.21 & 0.92 & 0.75 & LCR DROP/PVK ATTEX & 1.43 & 0.82 & 0.53 \\
MRW500/METEOSERVIS & 1.01 & 0.98 & 0.74 & & & & \\
\hline
\end{tabular}

field measurements compared to the reference intensity, the limits of the tolerance region calculated as described above (see Vuerich et al., 2009a for further details) are included as dashed lines on each plot.

For easier comparison, the instruments have been grouped according to the measuring principle employed. Also, the data analysis results are separately summarised below for the two categories of catching and non-catching type rain gauges. This reflects the fact that different conclusions can be drawn about the non-catching category at the present state of development and calibration of such instruments.

Scatter plots of measured rainfall rates against the reference ones are reported in Fig. 5 to illustrate the dispersion of deviations around the fitted trend lines for two sample gauges with a high (a) and low (b) $R^{2}$ value as reported in Table 2 .

\subsection{Catching type rain gauges}

As for the tipping bucket rain gauges, while the performance of non corrected instruments are not within the tolerance region (see Fig. 4a), the method applied by software corrected instruments confirms the possibility to improve the one-minute RI resolution and to provide accurate field measurements for the whole RI range experienced during the intercomparison (Fig. 4b). The method applied by pulse corrected instruments revealed the possibility to provide accurate field measurements at higher RI, even if their performance is limited by their resolution at lower RI (Fig. 4c). Catching type gauges using other measuring principles, except for weighing gauges, do not remain within the tolerance region (see Fig. 4d).

The achievable accuracy of weighing gauges (Fig. 4e) in field conditions can be improved by reducing the response time below one-minute and using appropriate filtering methods. The correlation coefficient of the best fit curve for
VRG101-VAISALA is very low, so the fit is not much representative for this sensor. The use of raw mass data, also available from the VRG101-VAISALA sensor, could improve the results.

\subsection{Non-catching type rain gauges}

This intercomparison is the first WMO test bed where noncatching type rain sensors were compared to catching type rain gauges and to a pit based RI composite working reference for the field measurement of one-minute RI.

During the intercomparison period, the non-catching type rain gauges needed low maintenance and few periodic checks (especially for the impact disdrometers and the microwave radar), thus this kind of instruments is considered particularly suitable for Automatic Weather Stations (AWS) or generally unmanned meteorological stations. Moreover LPMTHIES, PWD22-VAISALA and PARSIVEL-OTT have the advantage to determine the type of precipitation, to distinguish between solid and liquid precipitation and to provide present weather information (METAR and SYNOP codes). For further investigations concerning these aspects, the observations of the Vigna di Valle H24 meteorological station are also available to distinguish hail and rain events.

The non-catching type rain gauges were calibrated by the manufacturers prior to the intercomparison. Since no standard calibration procedure exists which is suitable for all the involved non-catching gauges, it was not possible to perform laboratory and field calibration of these instruments. Therefore factory calibration reports and information about calibration methods provided by manufacturers were the only sources of information available on the achievable accuracy of these instruments. This field intercomparison has shown the need to improve calibration methods adopted for noncatching rain gauges for one-minute RI measurements. 


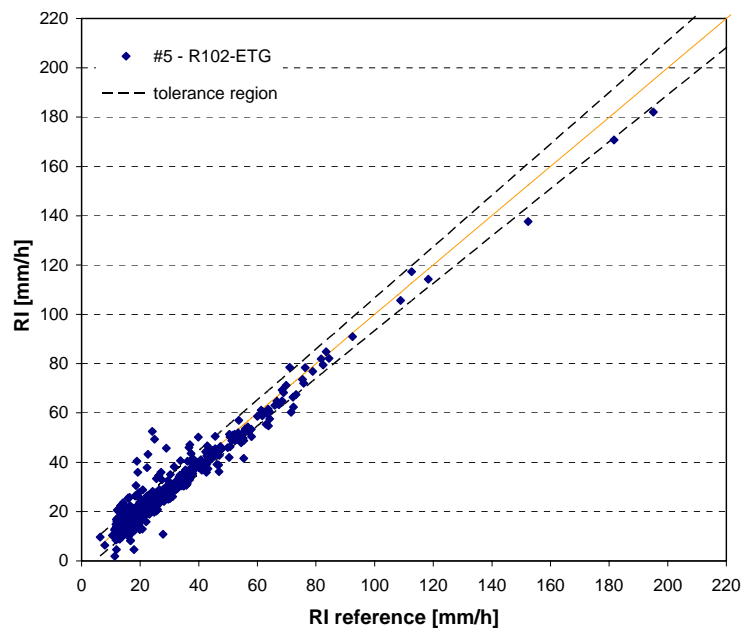

(a)

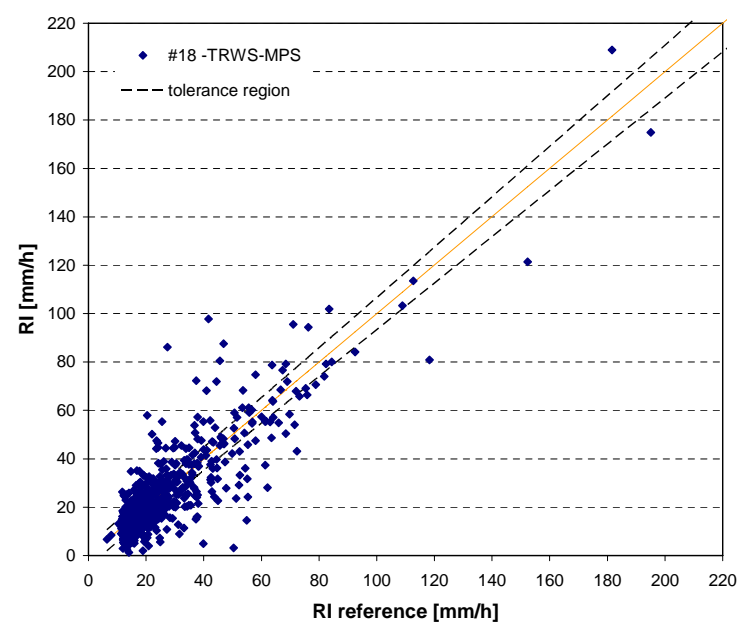

(b)

Fig. 5. Scatter plots of measured rainfall rates against the reference ones (from the data sheets in Vuerich et al., 2009a), illustrating the dispersion of deviations around the fitted trend lines for two sample gauges with a high (a) and low (b) $R^{2}$ value as reported in Table 2.

However, according to the results of this section (Fig. 4f) and Data Sheets, WXT510-VAISALA, LCR "DROP”-PVK ATTEX and PWD22-VAISALA rain gauges show a nonlinear behaviour compared to the RI reference in the full range or within some intensity ranges and their data are more spread than the data of other gauges. In particular: LCR "DROP"-PVK ATTEX shows a strong non-linearity above $80 \mathrm{~mm} \times \mathrm{h}^{-1}$; WXT510-VAISALA tends to overestimate RI and has a larger spread of data above $50 \mathrm{~mm} \times \mathrm{h}^{-1}$. On a one-minute time scale, PWD22-VAISALA tends to underestimate RI, with large dispersion of data. On the other hand, PARSIVEL-OTT and LPM-THIES optical disdrometers show a lower spread of data, a more linear behaviour in the full range and an overestimation trend. The correlation coefficients of the best fit curve for PWD22-VAISALA and LCR "DROP"-PVK ATTEX are very low, so the fits are not representative of these sensors.

\section{Conclusions}

The results of the analysis performed on highly accurate rain intensity measurements at the field test site of Vigna di Valle (Italy) confirmed the feasibility to measure and compare rainfall intensities on a one-minute time scale and provided information on the achievable measurement uncertainties. Due to the very high variability of rainfall intensity, the time synchronization of the instruments was crucial to compare their measurements. This should be properly taken into account while designing any measurement system, as two successive one-minute rainfall intensity measurements can differ much more than the measurements of two well synchronized instruments.

The results confirm that corrected tipping-bucket rain gauges performed better than uncorrected ones. The correction could be achieved either by electronically adding an extra pulse or by software based correction. The laboratory and field results confirmed that software correction is the most appropriate method. Very good results with respect to linearity, resolution enhancement and noise reduction could be achieved.

Catching gauges that do not use a funnel are sensitive to external factors, like wind and splash, which could affect the measurements. As a consequence, their noise level is generally increased in comparison to gauges using a funnel. The necessary filter algorithms for noise reduction could introduce a delay, longer time constants or other effects on the RI output. However, proper techniques could be used to reduce the noise in the measurements without introducing a delay and/or a longer time constant.

The best performing weighing gauges and tipping-bucket rain gauges were found to be linear over their measurement range. However, weighing gauges generally cover a wider range.

None of the non-catching rain gauges agreed well with the reference. Disdrometers tended to overestimate the rainfall intensity. Despite their very different calibration procedures, they agreed better to each other than to the reference. This indicated that they had a good degree of precision but were not as accurate as conventional gauges. The microwave radar and the optical/capacitive sensor tended to underestimate the rainfall intensity. For this reason, intercomparison quality control and synchronization procedures were developed to ensure the high quality of the intercomparison data set. These one-minute data would be available for further analysis. 
Acknowledgements. This work was performed within the WMO Field Intercomparison of RI Gauges. The authors are grateful to all members of the WMO Expert Team (ET) on "Surface-based instrument Intercomparisons and Calibration Method" and the International Organizing Committee (IOC) on "Surface-based Instrument Intercomparisons", and in particular to E. Lanzinger (the Project Leader), M. Leroy, Chair of the ET/IOC and L. Stagi (Site Manager of the Laboratory Phase) for their collaboration and continued stimulating discussion. The authors wish to thank C. Monesi for having elaborated most of the information synthetically presented in the graphs and the staff of ReSMA at the Italian Air Force site for technical assistance. A special thank is due to Gen. M. Capaldo, Col. P. Pagano and Col. G. Daddario, for their continuous support and encouragement before and during the project.

Edited by: S. C. Michaelides

Reviewed by: two anonymous referees

\section{References}

JCGM: Evaluation of measurement data - Guide to the expression of uncertainty in measurement. Joint Committee for Guides in Metrology, First edition, September 2008.

Keefer, T. O., Unkrich, C. L., Smith, J. R., Goodrich, D. C., Moran, M. S., and Simanton, J. R.: An event-based comparison of two types of automated-recording, weighing bucket rain gauges, Water Resour. Res., 44, W05S12, doi:10.1029/2006WR005841, 2008.

La Barbera, P., Lanza, L. G., and Stagi, L.: Influence of systematic mechanical errors of tipping-bucket rain gauges on the statistics of rainfall extremes, Water Sci. Technol., 45(2), 1-9, 2002.

Lanza, L. G., Leroy, M., Alexandropoulos, C., Stagi, L., and Wauben, W.: WMO Laboratory Intercomparison of Rainfall Intensity Gauges - Final Report, IOM Report No. 84, WMO/TD No. 1304, 2005.

Lanza, L. G. and Stagi, L.: Certified accuracy of rainfall data as a standard requirement in scientific investigations, Adv. Geosci., 16, 43-48, 2008,

http://www.adv-geosci.net/16/43/2008/.
Lanza, L. G. and Stagi, L.: High resolution performances of catching type rain gauges from the laboratory phase of the WMO Field Intercomparison of Rain Intensity Gauges, Atmos. Res., 94(4), $555-563,2009$.

Lanza, L. G. and Vuerich, E.: The WMO Field Intercomparison of Rain Intensity Gauges, Amos. Res., 94(4), 534-543, 2009.

Michaelides, S.: Preface of the Special Issue on Precipitation Measurement, Remote Sensing, Climatology and Modeling, Atmos. Res., 94(4), 511, 2009.

Molini, A., Lanza, L. G., and La Barbera, P.: Improving the accuracy of tipping-bucket rain records by disaggregation techniques, Atmos. Res., 77, 203-217, 2005a.

Molini, A., Lanza, L. G., and La Barbera, P.: The impact of tipping-bucket raingauge measurement errors on design rainfall for urban-scale applications, Hydrol. Process., 19, 1073-1088, $2005 b$.

Pavlyukov, Yu. B.: Precipitation measurement with automated tipping-bucket rain gauges, Russian Meteorol. Hydrol., 32(11), 711-718, 2007.

Ren, Z. and Li, M.: Errors and correction of precipitation measurements in China, Adv. Atmos. Sci., 24(3), 449-458, 2007.

Rodriguez J., Vos F., Below R., and Guha-Sapir, D.: Annual Disaster Statistical Review: the Numbers and Trends. Centre for Research on the Epidemiology of Disasters, Jacoffset Printers, Melin (Belgium), 2009.

Tokay, A., Wolff, D. B., Wolff, K. R., and Bashor, P.: Rain Gauge and Disdrometer Measurements during the Keys Area Microphysics Project (KAMP), J. Atmos. Ocean. Tech., 20, 14601477, 2003.

Vuerich, E., Monesi, C., Lanza, L. G., Stagi, L., and Lanzinger, E.: WMO Field Intercomparison of Rainfall Intensity Gauges. World Meteorological Organisation - Instruments and Observing Methods Rep. No. 99, WMO/TD No. 1504, 2009a.

Vuerich, E., Lanza, L. G., and Stagi, L.: WMO Field Intercomparison of Rainfall Intensity Gauges: the field calibration (Italy, 2007-2009), in: Rainfall in the urban context: forecasting, risk and climate change, Proc. 8th International Workshop on Precipitation in Urban Areas. St. Moritz, Switzerland, 10-13 December 2009, 268-272 (published on CD-ROM), $2009 \mathrm{~b}$.

WMO: Guide to Meteorological Instruments and Methods of Observation, WMO-No. 8, 7. Edn., World Meteorological Organization, Geneva, Switzerland, 2008. 